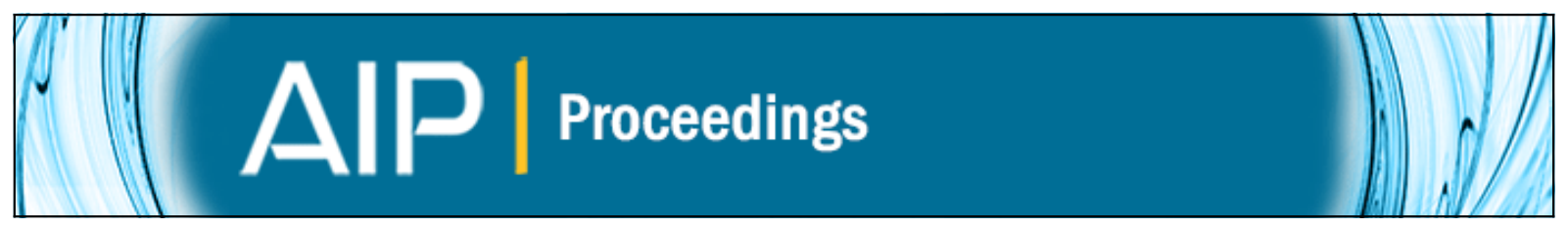

\title{
AIR-COUPLED SURFACE WAVE TRANSMISSION MEASUREMENT ACROSS A PARTIALLY CLOSED SURFACE-BREAKING CRACK IN CONCRETE
}

Seong-Hoon Kee and Jinying Zhu

Citation: AIP Conference Proceedings 1335, 169 (2011); doi: 10.1063/1.3591853

View online: http://dx.doi.org/10.1063/1.3591853

View Table of Contents: http://scitation.aip.org/content/aip/proceeding/aipcp/1335?ver=pdfcov

Published by the AIP Publishing

\section{Articles you may be interested in}

Using air-coupled sensors to determine the depth of a surface-breaking crack in concrete

J. Acoust. Soc. Am. 127, 1279 (2010); 10.1121/1.3298431

USING AIR-COUPLED SENSORS TO MEASURE DEPTH OF A SURFACE-BREAKING CRACK IN CONCRETE

AIP Conf. Proc. 1096, 1497 (2009); 10.1063/1.3114134

Air-Coupled Impact-Echo Method for NDT of Concrete

AIP Conf. Proc. 820, 1351 (2006); 10.1063/1.2184681

Measurement of surface wave transmission coefficient across surface-breaking cracks and notches in concrete J. Acoust. Soc. Am. 113, 717 (2003); 10.1121/1.1537709 


\title{
AIR-COUPLED SURFACE WAVE TRANSMISSION MEASUREMENT ACROSS A PARTIALLY CLOSED SURFACE-BREAKING CRACK IN CONCRETE
}

\author{
Seong-Hoon Kee and Jinying Zhu \\ Department of Civil, Architectural, and Environmental Engineering, the University of \\ Texas, Austin, TX 78712-0273
}

\begin{abstract}
Previous researchers have demonstrated that the transmission of surface waves is effective to estimate the depth of a surface-breaking crack in solids. However, most of the results were obtained using a well-defined crack (or notch) in laboratory. In fact, there is a critical gap to apply the theory to surface-breaking cracks in concrete structures subjected to external loadings where the cracks are generally ill-defined, and partially closed. In this study, the authors investigated transmission coefficients of surface waves across a partially closed surface-breaking crack in concrete subjected to monotonically increasing compressive loadings. First, a concrete beam $(0.5 \mathrm{X} 0.154 \mathrm{X}$ $2.1 \mathrm{~m}^{3}$ ) having two surface-breaking cracks with various crack widths was prepared in laboratory. Second, transmission coefficients of impact-induced surface waves were measured across a surfacebreaking crack in the concrete beam with increasing compressive loadings from 0 to $140 \mathrm{kN}(10 \%$ of the ultimate compressive strength of the concrete beam). External post-tensioning was used to apply the compression. For comparison purpose, sensitivity of surface wave velocity to compressive loading was also investigated. As a result, observations in this study reveal that transmission coefficient is a more sensitive acoustic parameter than phase velocity to evaluate a surface-breaking cracking in concrete subjected to compressive loadings.
\end{abstract}

Keywords: Partially Closed Crack, Air-Coupled Sensor, Leaky Rayleigh Wave, Concrete PACS: 43.20.El, 43.20.Hq, 43.35.Pt.

\section{INTRODUCTION}

Scattering field of surface waves caused by a surface-breaking crack can provide useful information of estimating the crack depth in solids. To surface waves with frequencydependent penetration depth, a surface-breaking crack acts as a low-pass filter. When incident surface waves $\left(\mathrm{R}_{\mathrm{i}}\right)$ propagate across a surface-breaking crack, the low frequency components of the surface waves will transmit to the forward scattering field with attenuation $\left(\mathrm{R}_{\mathrm{tr}}\right)$, while high frequency components will be reflected back. Consequently, transmission coefficients of surface waves $\left(R_{t r} / R_{i}\right)$ depend on frequency (or wavelength) of surface waves, and the crack depth.

Previous researchers have developed a non-destructive test (NDT) method based on surface-wave transmission measurements (the SWT method) to estimate the depth of a

Review of Progress in Quantitative Nondestructive Evaluation, Volume 30

AIP Conf. Proc. 1335, 169-174 (2011); doi: 10.1063/1.3591853

(C) 2011 American Institute of Physics 978-0-7354-0888-3/\$30.00 
surface-breaking crack in solids. Using ultrasonic transducers, Viktorov [1] experimentally developed the relationship between the surface wave transmission coefficient and the normalized crack depth $h / \lambda$, i.e., the ratio of crack depth to the wavelength, for a surfacebreaking crack in a solid. Angel and Achenbach [2] obtained $T_{r}$ and $h / \lambda$ relation based on an analytic model considering diffraction and scattering of Rayleigh wave by a surfacebreaking crack in a homogeneous elastic half-space domain. For concrete, a heterogeneous but globally isotropic material, Hevin et al. [3] obtained the transmission ratio of surface wave in frequency domain using numerical simulations, and proposed the cut-off frequency $(h / \lambda=0.3)$ method to estimate crack depth. Popovics and Song et al. [4-5] also obtained the $\operatorname{Tr}$ and $h / \lambda$ relationship through experiments and boundary element analysis. For surface wave transmission measurements, they used a self-calibrating procedure to eliminate surface coupling inconsistency and geometric attenuation effects. Recently the authors applied air-coupled sensors to improve test speed and repeatability of transmission measurements in concrete [6].

However, most of the results were obtained using a well-defined crack (or notch) in laboratory. In facts, there is a critical gap to apply the theory to surface-breaking cracks in concrete structures subjected to external loadings where the cracks are generally illdefined, and partially closed. Kendall and Tabor [7] investigated interfacial contact between solids using several methods including electrical, thermal, optical and ultrasonic assessment. Previous researchers (Baltazar et al. [8] and Kim et al. [9]) have demonstrated that ultrasonic waves are sensitive to evaluate rough surface in contact or imperfect interfaces. Pecorari [10] investigated scattering of surface waves by a partially closed surface-breaking crack in aluminum specimen and explored effects of external loadings on reflection and transmission coefficients of surface waves.

In this study, the authors investigated the transmission coefficients of surface waves across a partially closed surface-breaking crack in concrete through experimental studies. First, a concrete beam $\left(0.5 \times 0.154 \times 2.1 \mathrm{~m}^{3}\right)$ having two surface-breaking cracks with various crack widths was prepared in laboratory. Then, transmission coefficients of impactinduced surface waves were measured across a surface-breaking crack in the concrete beam with increasing external compressive loadings from 0 to $140 \mathrm{kN}(10 \%$ of the ultimate compressive strength of the concrete beam). For this purpose, the external post-tensioning was applied at the end of concrete beam. For comparison purpose, sensitivity of surface wave velocity to compressive loadings is also investigated.

\section{EXPERIMENT PROGRAM}

\section{$\underline{\text { Test Setup }}$}

A concrete specimen $\left(500 \times 154 \times 2100 \mathrm{~mm}^{3}\right)$ was prepared in laboratory. As shown in Figure 1, the specimen included three test regions: one crack-free region in the middle (test region I), and two regions with a surface-breaking crack with different crack widths from hair-line to $0.75 \mathrm{~mm}$. Two air-coupled sensors (PCB model No. 377B01) were used to measure leaky surface waves in three tests regions. The surface waves were generated by applying impact forces using steel balls having diameters of 13 and $8 \mathrm{~mm}$. 


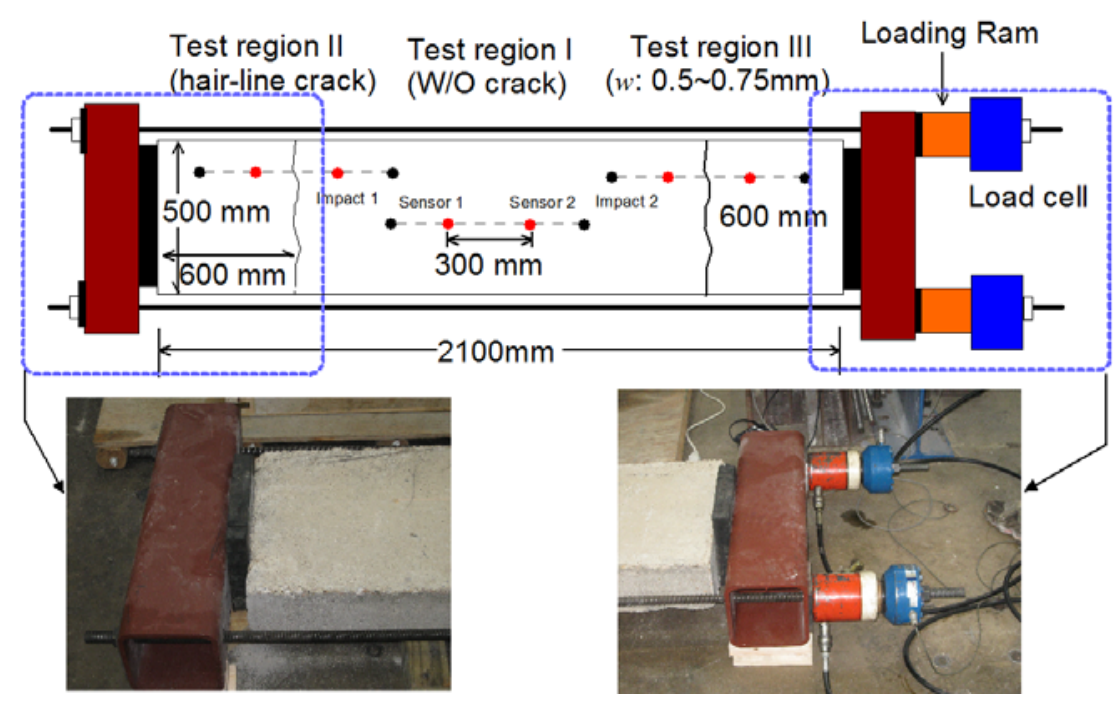

FIGURE 1. Test specimen, test regions, and setup for compressive loading.

In addition, external post-tensioning was applied at the end of the concrete specimen to investigate the effects of compressive loadings on transmission coefficients, and phase velocity of surface waves. The compressive loads were monotonically increased from 0 to $140 \mathrm{kN}(10 \%$ of nominal compressive strength of concrete beams) with 6 steps $(0,20,40$, 75,110 , and $140 \mathrm{kN}$ ). Two loading rams controlled by a hydraulic pump were placed to apply external loads. Magnitude of compressive loads was monitored by two load cells attached to the loading rams. In addition, rubber pads were used to prevent stress concentration at the concrete-steel interfaces.

\section{Data Acquisition and Signal Processing}

Transmission coefficient of surface waves was measured using a test setup based on the self-calibrating procedure. In the SC procedure, two sensors were located at the either side of a crack as shown in Figure 2. First, surface waves generated by an impact force applied on the one side of a crack were recorded by sensors 1 and 2, which are denoted as $V_{A B}$, and $\mathrm{V}_{\mathrm{AC}}$, respectively. Subsequently, surface waves generated by an impact source at the opposite side were measured by sensors 1 and 2 , which are $\mathrm{V}_{\mathrm{DC}}$, and $\mathrm{V}_{\mathrm{DB}}$. Next, transmission coefficients of surface waves were calculated in the frequency domain as follows:

$$
|\operatorname{Tr}(f)|=\left|\sqrt{\frac{\mathbf{S}_{A C} \mathbf{S}_{D B}}{\mathbf{S}_{A B} \mathbf{S}_{D C}}}\right|,
$$

where $\mathrm{S}_{i j}$ is the Fourier transform of the time domain signal $\mathrm{V}_{i j}$. To eliminate effects of geometric attenuation and material damping, $\operatorname{Tr}(f)$ measured in the crack regions were normalized by $\operatorname{Tr}_{0}(f)$ measured in the crack-free region (normalized transmission coefficient).

In addition, phase velocity of surface waves was calculated by the spectral analyses of surface waves (SASW) using the same signal data obtained from the SC procedure,

$$
V_{r}(f)=2 \pi f \frac{\Delta x}{\Delta \phi}
$$




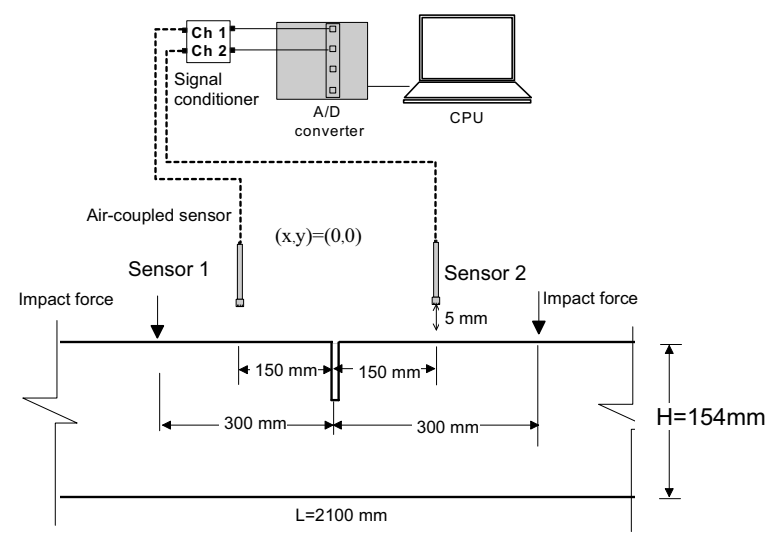

FIGURE 2. A data acquisition system to measure leaky surface waves.

where $\mathrm{V}_{\mathrm{r}}(f)$ is the phase velocity of surface waves in the frequency domain, $\Delta x$ is distance between sensor 1 and 2 (300 $\mathrm{mm}$ in this study), and $\Delta \phi$ is the phase difference of surface waves measured by sensors 1 and 2 .

A Hanning window was applied to the time domain signal to extract the Rayleigh wave component before spectral analyses. To improve signal-to-noise level, spectral coherence curve was calculated using Eq.(4), based on five repeated signals collected at the same location

$$
S C_{B C}(f)=\frac{\left|\sum G_{B C}(f)\right|^{2}}{\sum G_{B B}(f) \times \sum G_{C C}(f)},
$$

where $G_{B C}(f), G_{B B}(f)$ and $G_{C C}(f)$ are the cross spectrum and auto spectrum functions between the time domain signals $V_{A B}$ and $V_{A C}$, respectively. Similarly, $S C_{\mathrm{CB}}(f)$ can also be calculated from $V_{D B}$, and $V_{D C}$. The value of $S C(f)$ ranges from 0 to 1.0 . A value close to 1.0 indicates good signal quality and repeatability. Acceptable frequency ranges were determined where spectral coherence is higher than 0.98 .

\section{RESULT AND DISCUSSION}

\section{$\underline{\text { Transmission Coefficient }}$}

Figures 3 shows transmission coefficients of surface waves measured on the concrete specimen with increasing compressive forces from 0 to $140 \mathrm{kN}$. Figure $3(\mathrm{a})$ and 3 (b) show transmission coefficients of surface waves at frequencies of 25 and $40 \mathrm{kHz}$, which were generated by dropping steel balls with diameters of 13 and $8 \mathrm{~mm}$, respectively. Figure 4 show the normalized transmission variation with respect to the crack free region. For the crack-free region (region I), the surface wave transmission shows only very slight increase with increasing compressive forces. For test regions II and III, the initial transmission is below 0.1 in unloaded condition. However, the transmission gradually increases with the compressive force, and attained to $20 \sim 60 \%$ of $\operatorname{Tr}_{n, 0}$ when compressive forces increased to $140 \mathrm{kN}$ (Figure 4).

Results shown in Figures 3 and 4 indicate that the initial crack width and the frequency of incident surface waves affect surface wave transmission across a crack under compression loading. At a given frequency, surface wave transmission measured on a hairline crack (test region II) is more sensitive to compression loads than the measurement on test region III with a wide crack. 
(a) $\mathrm{f}_{\mathrm{c}}=25 \mathrm{kHz}$

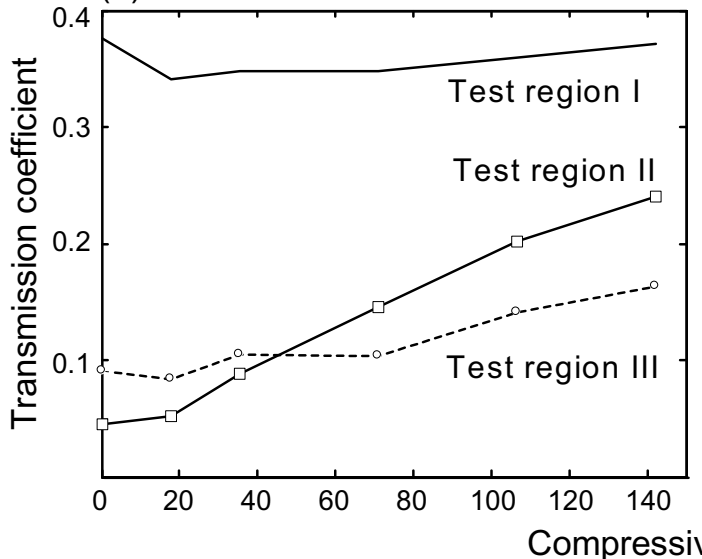

(b) $\mathrm{f}_{\mathrm{c}}=40 \mathrm{kHz}$

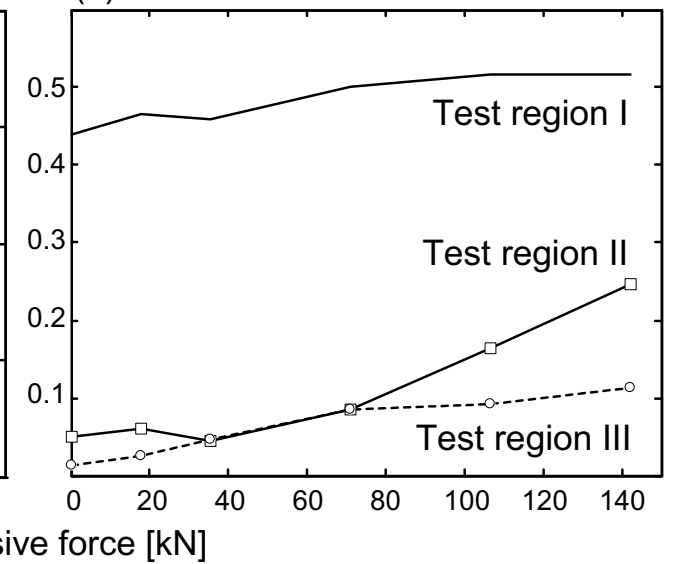

FIGURE 3. Transmission coefficient versus compressive force: (a) $25 \mathrm{kHz}$, and (b) $40 \mathrm{kHz}$.

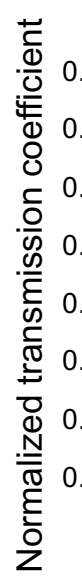

(a) $\mathrm{f}_{\mathrm{c}}=25 \mathrm{kHz}$

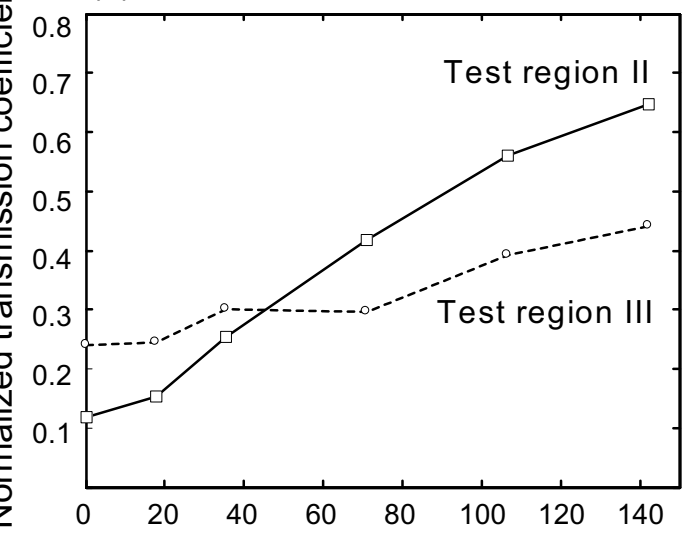

(b) $\mathrm{f}_{\mathrm{c}}=40 \mathrm{kHz}$

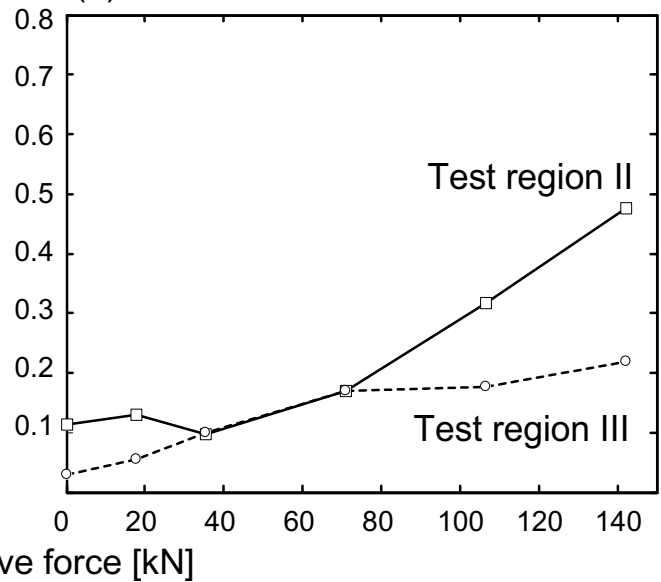

FIGURE 4. Normalized transmission coefficient versus compressive force: (a) $25 \mathrm{kHz}$, and (b) $40 \mathrm{kkHz}$.
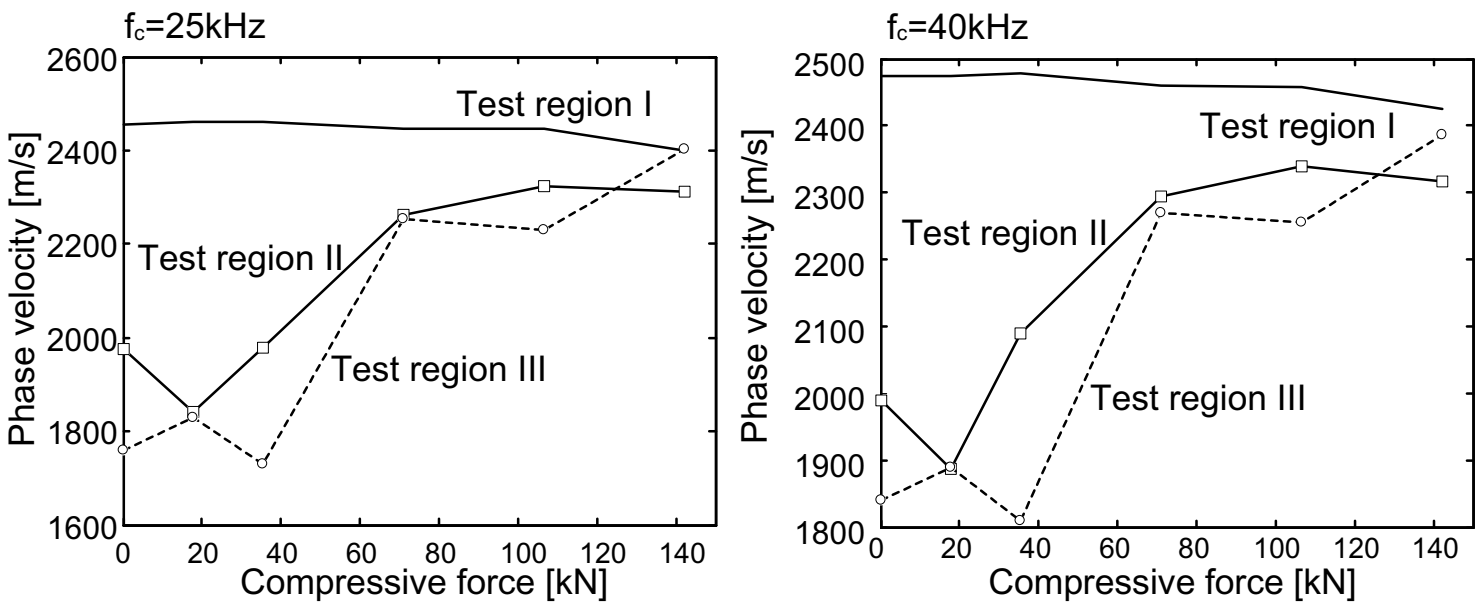

FIGURE 5. Effects of external compressive force on phase velocity of surface waves in frequencies (a) $25 \mathrm{kHz}$ and (b) $40 \mathrm{kHz}$. 


\section{Phase Velocity}

Figures 5(a) and (b) show effects of compressive forces on phase velocity of surface waves at frequencies of 25 and $40 \mathrm{kHz}$, respectively. In the crack-free region, the phase velocity of surface waves is not sensitive to changes of compressive forces, and is around 2400 to $2460 \mathrm{~m} / \mathrm{s}$. In test region II, the phase velocity starts to increase at load level $20 \mathrm{kN}$, and reaches peak value around $2350 \mathrm{~m} / \mathrm{s}$ at $100 \mathrm{kN}$. In region III, the velocity increase starts at a little bit high load level of $40 \mathrm{kN}$, and reaches $2400 \mathrm{~m} / \mathrm{s}$ at $140 \mathrm{kN}$. In both cases, the phase velocity reaches above $96 \%$ of the velocity in crack free region for compressive loading from 60 to $140 \mathrm{kN}$. By comparing to the surface wave transmission result, it can be concluded that the transmission measurement is more sensitive than the phase velocity to existence of cracks in concrete subjected to external compressive loadings.

\section{SUMMARY}

1) For the crack-free region, transmission coefficients and phase velocities do not change much with increasing compressive forces from 0 to $140 \mathrm{kN}$, which corresponds to $10 \%$ of compressive strength of the concrete beam.

2) For the test regions II and III, the normalized transmission coefficients of surface waves across a surface-breaking crack gradually increased with increasing compressive forces, and attained to $20 \sim 60 \%$ of $\operatorname{Tr}_{\mathrm{n}, 0}$ when compressive forces increased to $140 \mathrm{kN}$. However, under compressive loading from 60 to $140 \mathrm{kN}$, the phase velocity of surface waves is about $96 \%$ of the velocity in crack free regions.

3) Observations in this study reveal that the transmission coefficient is a sensitive acoustic parameter to evaluate a surface-breaking cracking in concrete structures subjected to external compressive loadings.

\section{REFERENCES}

1. I.A. Viktorov, "Rayleigh Waves and Lamb waves-Physical Theory and Application," Plenum, New York, 1967, 57-65.

2. Y.C. Angel, and J.D. Achenbach, J. Acoust. Soc. Am, 75, 313-319 (1984).

3. G. Hevin, O. Abraham, H.A. Petersen, M. Campillo, NDT \& E International, 31, 289298 (1998).

4. J. S. Popovics, W-J. Song, M. Ghandehari, K. V. Subramaniam, J. D. Achenbach, and S. P. Shah, ACI Material journal, 97, 127-135 (2000).

5. W-J. Song, J. S. Popovics, J. C. Aldrin, and S. P. Shah, J. Acoust. Soc. Am,113, 717725 (2003).

6. S. H. Kee and J. Zhu, Journal J. Acoust. Soc. Am,127,1279-1287 (2010).

7. K. Kendall, and D. Tabor, Proc. Roy. Soc. London A 323, 321-340 (1971).

8. A. Baltazar, S.I. Rokhlin, and C. Pecorari, Journal of Mech. Phy. Solids, 50, 12571416 (2002).

9. J.-Y. Kim, A. Baltazar, and S.I. Rokhlin, Journal of Mech. Phy. Solids, 52, 1911-1934 (2004).

10. C. Pecorari, Wave Motion, 33, 259-270 (2001). 